\title{
Análisis neotectónico de la falla Río Seco, ciudad de Valledupar, Cesar.
}

\section{Neotectonic analysis of Rio Seco fault, Valledupar, Cesar}

\author{
Kandy Manuela Teherán Ochoa ${ }^{1}$, Luis Carlos Tapia Vela².
}

\section{Resumen}

Objetivo: analizar neotectónicamente la falla del río seco, En la ciudad de Valledupar.

Metodología: para determinar si la actividad sísmica reciente se relaciona con dicha falla, se realizó

Palabras Claves:

Amenaza sísmica, Falla Rio Seco, Neotectónica. una identificación, clasificación y análisis de rasgos morfotectónicos del trazo de la misma en depósitos recientes. Haciendo uso de fotografías aéreas e imágenes satelitales.

Resultados: análisis de las diferentes expresiones morfotectónicas en los depósitos recientes, lo que permitió plantear el trazo de la falla sobre el cuaternario, y en la fase de campo se determinaron algunas características cinemáticas, comprobando los cambios morfológicos producidos, tales como ríos deflactados, laguna de inundación, manantiales y discontinuidades como diaclasas.

Conclusiones: estos cambios indicaron que la Falla Rio Seco tiene actividad reciente y está afectando los depósitos cuaternarios. Además, se estableció que la falla continúa con su orientación NEE hasta la cuenca Cesar-Ranchería. Se concluyó que la Falla Río Seco tiene actividad reciente y constituye una amenaza significativa para la ciudad.

\begin{abstract}
Objective: to analyze neotectónicamente the fault of the dry river, In the city of Valledupar.

Methodology: to determine if the recent seismic activity is related to this failure, an identification, classification and analysis of morphotectonic traits of the trace of the same in recent deposits was made. Making use of aerial photographs and satellite images.

Results: analysis of the different morphotectonic expressions in the recent deposits, which allowed to outline the fault line on the quaternary, and in the field phase some kinematic characteristics were

Keywords: determined, checking the morphological changes produced, such as deflated rivers, lagoon of flood, springs and discontinuities as diaclases.

Conclusions: these changes indicated that Falla Rio Seco has recent activity and is affecting Quaternary deposits. In addition, it was established that the fault continues with its NEE orientation to the Cesar-Ranchería basin. It was concluded that the Falla Río Seco has recent activity and constitutes a significant threat to the city.
\end{abstract}

Seismic threat, Rio Seco Fault, Neotectonic.

1 Fundación Universitaria del Área Andina, Correo electronico: kateheran@areandina.edu.co

2 Autor de correspondencia,Fundación Universitaria del Área Andina. Correo electronico: Itapia2@areandina.edu.co

Pág 40 Como citar este artículo: K. Teheran., y L. Tapia, "Análisis neotectónico de la falla río seco ciudad de Valledupar, Cesar", Investigación e Innovación en Ingenierias, vol. 6, n. 1, pp. 40 - 57. 2018. DOI: https://10.17081/invinno.6.1.2774 


\section{Introducción}

La Neotectónica se basa principalmente en el estudio de fallas con actividad sísmica reciente, abarcando un tiempo que va desde el mioceno hasta la actualidad. Su fin es determinar la relación que existe entre los movimientos de las fallas y la actividad sísmica reciente del área, y su descripción y caracterización han servido para evaluar la peligrosidad sísmica de una región [1, 2]. La Neotectónica suele utilizarse en la topografía moderna y el relieve actual, lo que permite conocer con cierta facilidad dichas estructuras recientes.

A lo largo de la historia los terremotos han producido daños inmensos, sobre todo en los bienes y construcciones humanas, dado que suelen ser inesperados e impredecibles. Por esta razón en las últimas décadas se ha incrementado el interés por el estudio de las causas y fenomenología de estos eventos.

En estas circunstancias, el objetivo principal de este trabajo consistió en realizar un análisis neotectónico de la Falla Río Seco para la modificación del mapa de amenaza del municipio de Valledupar.

Ubicada al noroccidente del municipio de Valledupar, departamento del Cesar, con dirección EW a N70E, la Falla Río Seco se extiende por 70 km, siguiendo en parte el curso de los ríos: Río Seco, Los Mangos y San Sebastián [1]. El estudio de la Falla Río Seco es necesario para conocer el potencial de esta como generadora de sismos y para consolidar un registro bibliográfico que contribuya en la modificación del mapa de amenazas de Valledupar.

\section{Localización}

a Falla RíoSeco está ubicada en el extremo noroccidental del municipio Valledupar en el departamento del Cesar, que corresponde al sector suroriental de la Sierra Nevada de Santa Marta. El área del proyecto, en la que dicha Falla se encuentra enmarcada, comprende 14 kilómetros cuadrados, con las siguientes coordenadas: al noroccidente 1088000 y 1666000; y al suroriente 1097000 y 1664000 (ver Figura 1).

Como citar este artículo: K. Teheran., y L. Tapia, "Análisis neotectónico de la falla río seco, ciudad de Valledupar, Cesar", Investigación e Innovación en Ingenierias, vol. 6, n. 1, pp. 40 - 57. 2018. DOI: https://10.17081/invinno.6.1.2774 


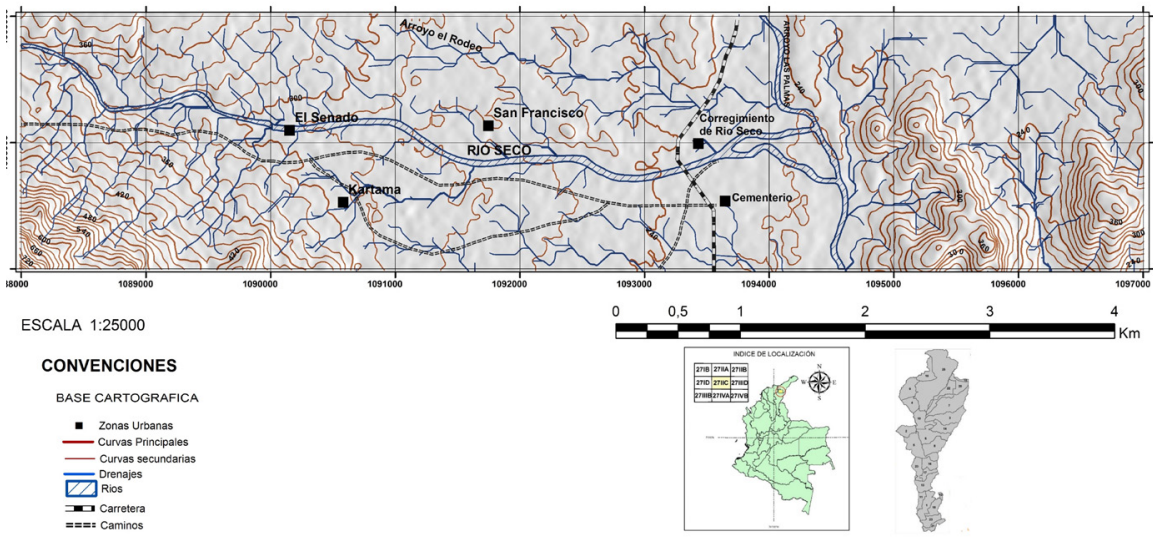

Figura 1.

Mapa de localización del área de estudio. Fuente: Autores.

\section{Metodología}

Inicialmente se recolectó información en lo que refiera a cartografía geológica (plancha 26 y 27 del estado de la Cartografía Geológica de Colombia del SGC), geomorfología e imágenes de satélite (Landsat 8). La información tomada de estas fuentes fue comprobada en campo. En este sentido, fue necesario analizar fotografías aéreas, lao que permitió conocer información concerniente a vías de acceso, drenajes, litologías, geomorfología y estructuras. Este estudio fotogeológico tuvo como fin último la creación de un mapa fotogeológico en el que se evidenciaran las características relacionadas anteriormente. Posteriormente, se realizó un estudio en campo de las geoformas presentes en la zona, debido a que estas sirven como indicador de los movimientos que ha tenido el subsuelo a lo largo del tiempo geológico, en este caso, un tiempo geológico reciente.

Muchas de las fallas activas existentes poseen registro sismológico de focos asociados a esta, como es el caso de la Falla Río Seco, que presenta una actividad moderada. Justamente, ello hace necesario la realización de un estudio neotectónico con el cual podamos conocer movimientos relativamente recientes.

Concretamente, se estudió la geometría estructural de la falla, determinando así la longitud, orientación y buzamiento. La toma de estos datos estructurales se realizó por tramos, debido a que estos pueden cambiar a lo largo de toda la falla y es claro que la falla puede presentar curvaturas, lo cual también se requeriría estudiar. 
Todo lo anterior se hizo con la intención de lograr como producto la caracterización de la geometría cinemática y dinámica de la falla, y así establecer y determinar las zonas de amenaza.

Se realizó entonces un mapa neotectónico en el cual se evidencian las diferentes geoformas producidas por el movimiento de la Falla Río Seco, y en particular la afectación que ha tenido sobre los depósitos cuaternarios como son las terrazas aluviales y los abanicos y gravas, comprobando así su actividad reciente.

\section{Marco geológico regional}

En el Cesar, departamento localizado en la parte nororiental de Colombia se presentan los tres tipos de rocas: ígneas, metamórficas y sedimentarias. Se han distinguido tres regiones con características geológicas diferentes, lo que le otorga gran diversidad geológica al departamento. En área sur del departamento se encuentra la región norte de la Cordillera Oriental, Serranía del Perijá, conformada por rocas de composición metamórficas, sedimentarias e ígneas, siendo estas últimas las de predominancia, con la presencia de cuerpos tanto intrusivos como volcánicos; a estas les siguen las metamórficas y, por último, aparecen las rocas sedimentarias, que conforman principalmente la parte plana del departamento [3]. Al norte del departamento del Cesar se localiza la Sierra Nevada de Santa Marta, más exactamente la parte sur de este particular relieve montañoso de base más o menos triangular. En esta región afloran rocas ígneas, metamórficas y sedimentarias, siendo las primeras las más abundantes con la presencia de pórfidos keratofídicos verdes, espilitas y otras rocas volcánicas o hipoabisales, además aparecen: Granitoides de la Sierra Nevada de Santa Marta, Batolito de Atanquez, Volcánico Ignimbrítico, Plutón de Nueva Lucha, Volcánico Riolítico, Pórfidos cretácicos, Lacolito de Atanquez. En tanto que entre las rocas metamórficas afloran la Granulita de los Mangos y el Neis de Los Muchachitos [4]. Y en cuanto a las rocas sedimentarias se encuentran: la Secuencia de la Cuchilla Carbona, Formaciones Corual y Los Indios, Formación Guatapurí, Grupo Cogollo y Formación Zambrano [5]. 


\section{Marco geológico local}

En el marco local se definen tres unidades litológicas. La primera es la Unidad Ignimbrita de Los Clavos, conformada por cantos de diferentes tamaños desde guijos guijarros y gravas, con composición félsica a intermedia, predominando las ignimbritas [6]. En la Figura 2A se observa una arenisca tobacea cristalina intermedia con un índice de color de $35 \%$, textura porfidoclástica, pórfidos de fragmentos líticos (autolitos). Asimismo, aparecen vacuolas, producto de la desgasificación al momento de su enfriamiento rápido, y minerales como cuarzo, feldespato y plagioclasas. Pero, por otra parte, también se encuentran tobas andesitas como se observa en la Figura 2B con tonalidad gris violáceo, intermedia, textura porfirítica, con fenocristales de plagioclasas, que presenta grietas de desgasificación. Hay presencia de rocas de composición félsica, como traquitas, como se observa en la Figura 2C, en la que aparece una traquita de color rosado pálido, con un índice de color bajo de alrededor de $3 \%$, de textura afanítica que se encuentra levemente meteorizada. Esta presenta grietas de desgasificación, y los minerales encontrados son en su mayoría feldespatos, plagioclasas, y en menor cantidad, cuarzo.

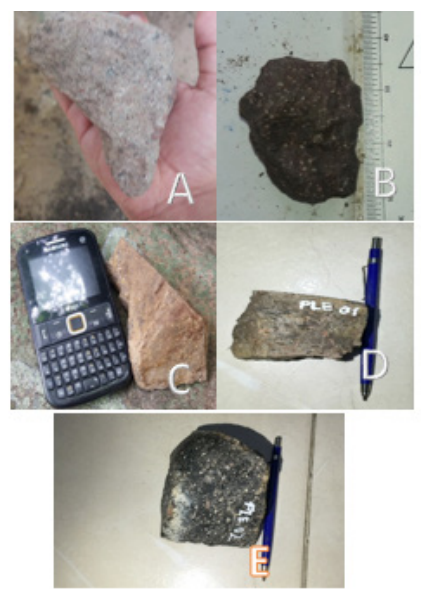

Figura 2.

Muestras de mano.

(A) Arenisca Tobacea

Cristalina, (B) Toba

Andesita (C) Traquita

(D) Riolita (E) Dacita

Fuente: Autores.

Una segunda unidad, denominada Riolita de Golero, corresponde a rocas ígneas de tipo volcánico y de composición ácida [6]. Esta presenta alta meteorización, producto de los flujos de agua proveniente de los abanicos aluviales y de otros agentes erosivos como el viento. Al este de la zona se encuentran cantos de composición riolítica (Figura 2D), de color gris claro y textura porfirítica con fenocristales de feldespato en forma subhedral, además contiene cristales de plagioclasa y gran cantidad de cuarzo. Por último, se encuentra dacita (Figura 2E), de color gris oscuro y textura afanítica, presentan anfíboles, representados en biotitas y horblendas con alteración hidrotermal de clorita. Estos cantos rodados han sido producto de la dinámica fluvial, transportados a través del curso del río. Paralelos a este se define la tercera unidad, compuesta por terrazas aluviales de edad 
geológica reciente [1]; estas geoformas se encuentran en ambos costados del cauce del río Seco en su parte baja. Se trata de una zona ligeramente inclinada con sedimentos suaves. Los depósitos no consolidados y con alta permeabilidad se hallan constituidos por bloques, cantos, guijos y gravas redondeadas de composición ígnea principalmente. Fueron encontrados en los cursos del arroyo las palmas.

\section{Marco tectónico regional}

El departamento del Cesar enmarca un sector del sistema montañoso de la Sierra Nevada de Santa Marta y parte de la Serranía del Perijá. Estas comprenden la parte norte del departamento e inciden en la tectónica de la región, debido a su amplia formación tectónica [6].

La Sierra Nevada de Santa Marta se ha considerado como una entidad geológica independiente, la cual sufrió una rotación en sentido horario durante el periodo cenozoico y esto produjo una fragmentación del basamento que se encontraba adyacente al occidente. Este movimiento de rotación se presentó en toda la parte noroccidental de Sudamérica, por lo que se puede concluir que también la Serranía del Perijá fue producto de este movimiento y, debido a esto, los dos sistemas conforman una sola entidad geotectónica con una evolución común y única [6]. Las fallas principales que limitan esta provincia geotectónica son la Falla de Occa, limitando la parte norte con tendencia dextral; la Falla Santa Marta-Bucaramanga al oeste y suroeste, con tendencia sinestral; y por último la Falla Perijá-el Tigre al sureste [7]. Sin embargo, aparte del movimiento horizontal, las dos primeras fallas antes mencionadas tienen tendencia vertical inversa.

Cabe anotar que las fallas localizadas en este sector son continuas, y hacen parte de extensos sistemas interconectados entre sí. En el área estudiada se presentan numerosos lineamientos que en términos generales se pueden agrupar en dos familias, las cuales presentan dos tendencias en diferentes direcciones. La primera es el lineamiento NE-SW de mayor longitud, y la segunda familia, que corta a la anterior, lo conforma el lineamiento NW-SE [1]. El lineamiento NE-SW es más extenso, y a diferencia del anterior se evidencia a escala regional. Este lineamiento atraviesa el macizo rocoso de la SNSM y la Serranía del Perijá.

También se describen fallas pertenecientes a este lineamiento en zonas de la SNSM como Atiquimaqueo, Curiba, Mamancana, Tierra Nueva, RóoSeco, Ariguanicito, Las Minas, Maìzmorocho, El Golero y otras sin denominación en la parte sur. Y en la parte de la Serranía del Perijá incluye las fallas Arenas Blancas, San José de Oriente y Media Luna. Este lineamiento ejerce un control en gran parte del drenaje y en el desarrollo geomorfológico del departamento del Cesar.

Entre las fallas principales que conforman la SNSM, la que obedece a este lineamiento es la Falla de Oca, de lo que se deduce que las fallas con menor longitud en esta dirección fueron producidas por

Como citar este artículo: K. Teheran., y L. Tapia, "Análisis neotectónico de la falla río seco, ciudad de Valledupar, Cesar", Investigación e Innovación en Ingenierias, vol. 6, nº 1, pp. 40 - $57 .$, 2018. DOI: https://10.17081/invinno.6.1.2774 
esta falla principal, incluyendo aquí la Falla Río Seco [8].

El lineamiento NW-SE corta el lineamiento anterior, el cual es más corto y puede observarse a menor escala. Este sistema es de mayor densidad debido a que presenta mayor número de fallas. El lineamiento NE-SW no estaba presente en el sistema de fallas NW-SE, por lo tanto, su origen se considera posterior a esta [8].

\section{Actividad sísmica}

En torno a la falla se han presentado series de focos sísmicos datados desde junio de 1993 a septiembre de 2015, con magnitudes variables entre 1.3 y 4.4 en la escala de Richter y profundidades entre 0 y $94 \mathrm{~km}$ (ver Tabla 1). Esta información da cuenta de la constante amenaza que constituye para Valledupar la cercanía a esta falla moderada [9]

\begin{tabular}{|l|l|l|l|l|}
\hline Fecha & Magnitud & Longitud & Latitud & $\begin{array}{l}\text { Profundidad } \\
(\mathrm{km})\end{array}$ \\
\hline $28 / 09 / 2001$ & 3.3 & -73.175 & 10.579 & 40 \\
\hline $16 / 07 / 2010$ & 2.5 & -73.224 & 10.598 & 0 \\
\hline $06 / 11 / 2011$ & 1.5 & -73.420 & 10.571 & 90.5 \\
\hline $20 / 04 / 2012$ & 2.4 & -73.312 & 10.648 & 70 \\
\hline $16 / 07 / 2012$ & 2 & -73.478 & 10.569 & 20.4 \\
\hline $13 / 12 / 2011$ & 2.4 & -73.338 & 10.649 & 0 \\
\hline $25 / 08 / 2013$ & 3.9 & -73.306 & 10.594 & 89.3 \\
\hline $29 / 08 / 2013$ & 1.7 & -73.248 & 10.572 & 83.1 \\
\hline $14 / 01 / 2014$ & 1.3 & -73.261 & 10.597 & 89.3 \\
\hline $16 / 01 / 2014$ & 1.3 & -73.425 & 10.602 & 71.3 \\
\hline $27 / 02 / 2014$ & 1.9 & -73.431 & 10.609 & 77.1 \\
\hline $16 / 03 / 2014$ & 1.7 & -73.216 & 10.664 & 14.4 \\
\hline $23 / 03 / 2014$ & 4.4 & -73.404 & 10.639 & 8 \\
\hline $21 / 09 / 2014$ & 2.1 & -73.231 & 10.562 & 33.6 \\
\hline $01 / 11 / 2014$ & 1.3 & -73.358 & 10.639 & 83.9 \\
\hline $02 / 05 / 2015$ & 1.4 & -73.181 & 10.582 & 89.2 \\
\hline $15 / 06 / 2015$ & 2.3 & -73.221 & 10.634 & 94 \\
\hline & & & & \\
\hline
\end{tabular}

Tabla 1.

Sismos asociados a la falla Río Seco, desde 2001 Fuente: SGC (2015). 


\section{ESTUDIO FOTOGEOLÓGICO}

Para la realización del mapa fotogeológico se tomó como base el mapa topográfico. Se cartografiaron drenajes, curvas de nivel, caminos, carreteras, casas, y se delimitaron las diferentes litologías diferenciadas en las fotografías aéreas. En el mapa también se refleja con exactitud el trazo de la Falla Río Seco, que se extiende en dirección EW, atravesando la unidad ignimbrita de Los Clavos, y se encuentra inferida en la zona de las terrazas y abanicos aluviales y gravas (ver Figura 3).

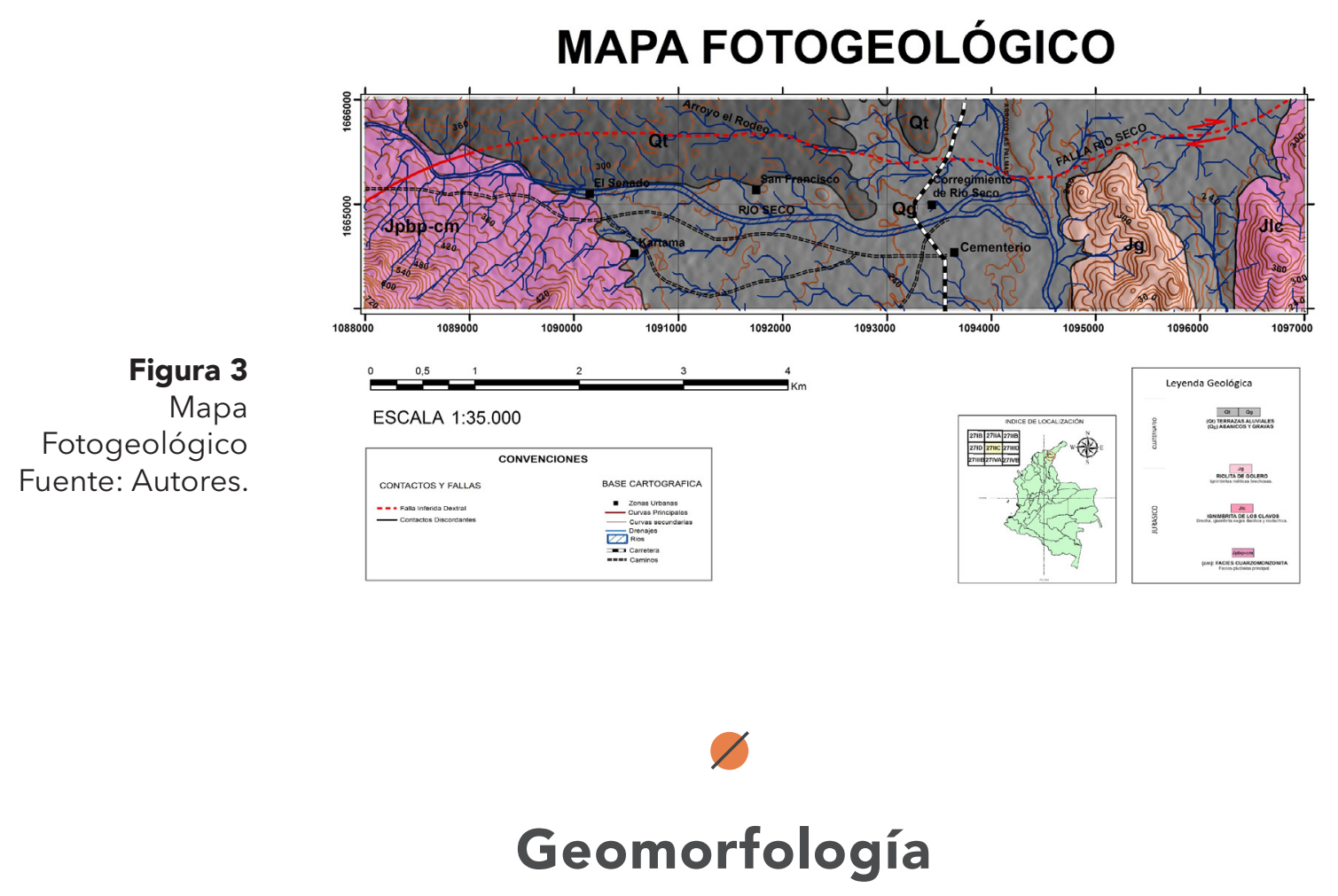

Geomorfológicamente, el área de estudio se encuentra enmarcada en relieves con pendientes suaves en forma de flancos semi-alargados y sub-redondeados, cubiertos por depósitos de escombro y depósitos aluviales matriz. Estos se componen de arena fina y sus clastos de forma angulosa que comprenden guijos, guijarros y bloques de composición ignimbrita provenientes del curso de la quebrada, y están ubicados al piedemonte de la colina (Figura 4). Al este, se encuentra una penillanura

Como citar este artículo: K. Teheran., y L. Tapia, "Análisis neotectónico de la falla río seco, ciudad de Valledupar, Cesar", Investigación e Innovación en Ingenierias, vol. 6, n. 1, pp. 40 - 57. 
compuesta por terrazas y abanicos aluviales provenientes del piedemonte. Los cursos fluviales han sido afectados por procesos fluviales manifestados en incisión tanto vertical como lateral. También hay cantos rodados, producto del transporte en el canal fluvial, como se observa en la Figura 5, que son transportados por las corrientes de los diferentes arroyos del área como el Arroyo Medio La Vega que va en sentido W-E y El Arroyo Las Palmas, con sentido N-S. Todos estos, junto con las quebradas, confluyen en el arroyo principal de Río Seco.

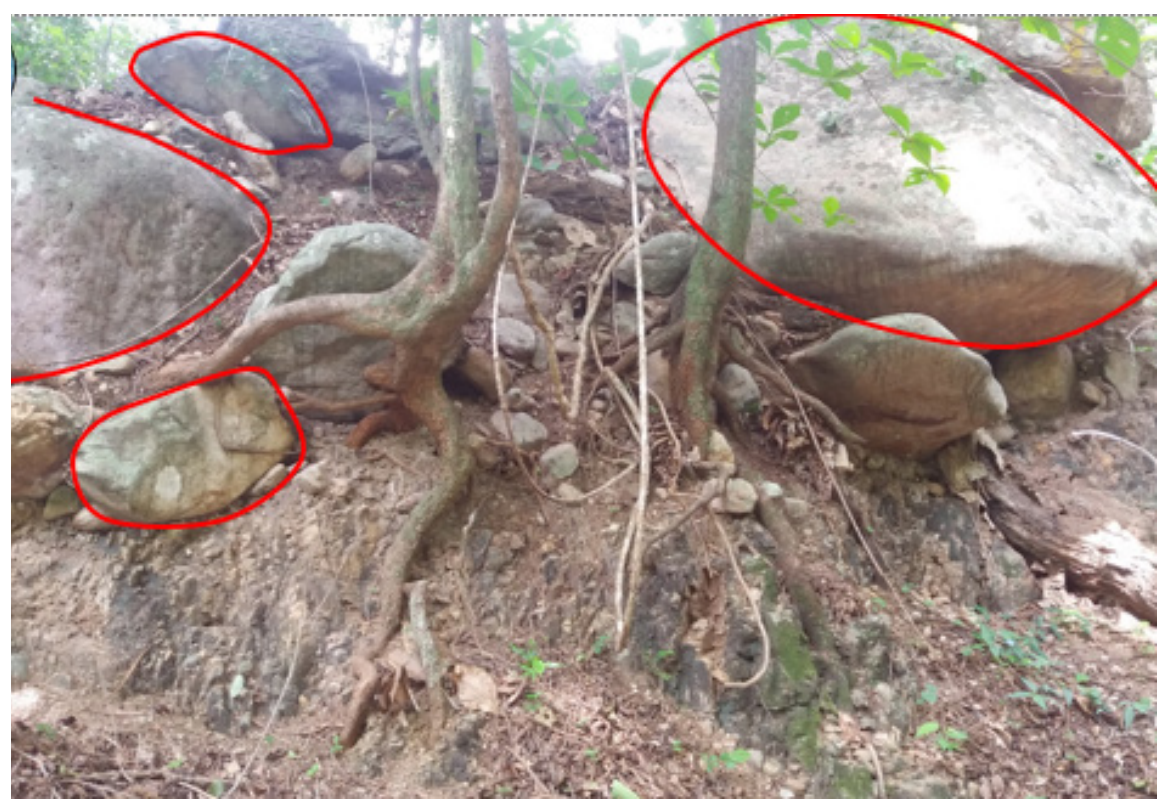

\section{Figura 4.}

Geomorfología. Se observan guijos, guijarros y bloques matriz soportados de arena fina Fuente: Autores.

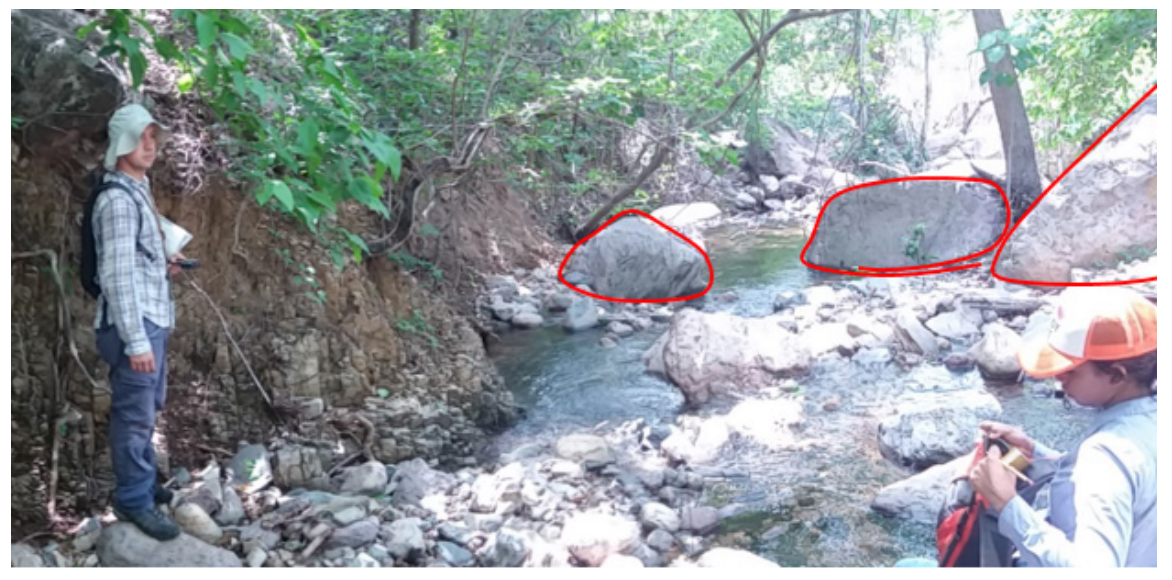

Figura 5.

Geomorfología. Se observa cantos de diversos tamaños transportados por procesos fluviales Fuente: Autores. 


\section{Análisis tectónico de la falla Río Seco}

A lo largo de su evolución tectónica, la falla Rio Seco ha estado en constante movimiento [1], lo que se reflejan en la superficie por medio de indicadores geomorfológicos característicos de las fallas. Esto ayuda a determinar la evolución que ha tenido en el tiempo. En la zona estudiada, la falla afecta la formación ignimbrita de Los Clavos, Riolita de Goleros y abanicos recientes. En dirección W-E se presentan geoformas generadas por la falla, como la unidad cronoestratigráfica ignimbrita de Los Clavos. Justamente, en la Figura 6, se aprecian tres colinas consecutivas afectadas por el trazo de la falla, formando tres silletas con niveles diferentes; la primera con gran altura y pendientes altas, la segunda, con altura moderada, y la tercera, con pendiente baja. Todas estas se encuentran alienadas en dirección al trazo de la Falla NEE.

Figura 6

Tres silletas de falla alineadas al trazo de la Falla Río Seco

Fuente: Autores.

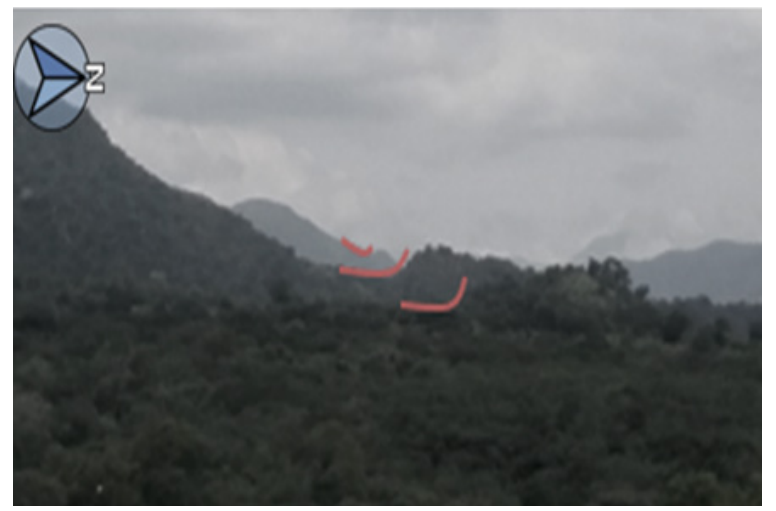

Alineada al trazo de la falla en dirección WE, se encuentra una fuente de agua que aflora del subsuelo. Normalmente en las zonas de falla las cavidades permiten la ascensión de aguas con mayor facilidad que en los sectores circundantes. El manantial fluye de las rocas de la formación ignimbrita de Los Clavos, y está rodeado por coluviones. El curso del agua confluye en la quebrada que va en dirección SN. En la Figura 7, se observa más detalladamente la fuente de agua rodeada por los coluviones.

\footnotetext{
Figura 7

Manantial

producido por la

falla Río Seco

Fuente: Autores.
}

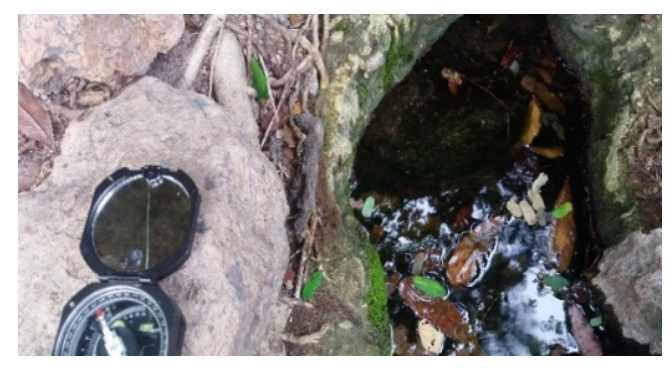

Como citar este artículo: K. Teheran., y L. Tapia, "Análisis neotectónico de la falla río seco, ciudad de Valledupar, Cesar", Investigación e Innovación en Ingenierias, vol. 6, n. 1, pp. 40 - 57. 2018. DOI: https://10.17081/invinno.6.1.2774 
En dirección Este, el curso fluvial ha sido afectado por el trazo de la falla. La Figura 8 evidencia el curso del río en dirección EW. Se presentan cantos rodados en el lecho del curso que han sido afectados por procesos de erosión fluvial y transporte. El curso fluvial es interrumpido en la superficie y se filtra al subsuelo, debido a que su nivel es inferior a la falla y continúa su cauce en la superficie a aproximadamente 50 metros de distancia, siguiendo el curso fluvial en dirección NE.

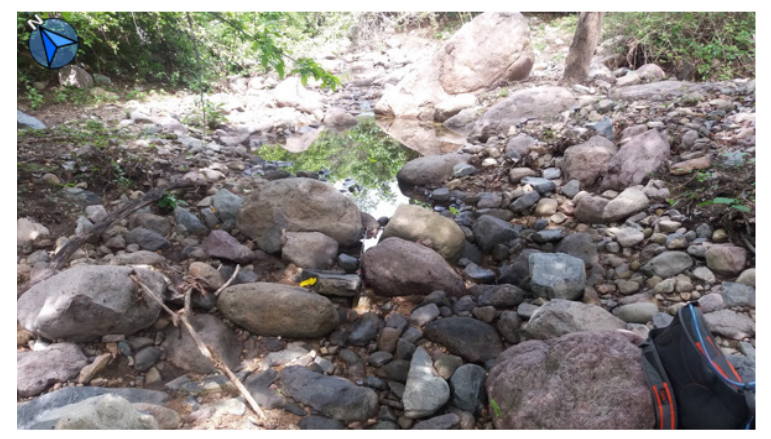

Figura 8.

Curso fluvial filtrado en el trazo de la falla Río Seco

Fuente: Autores.

En la Figura 9, se observa que el lecho de este cauce ha sido afectado por procesos de erosión fluvial y transporte, lo que ha originado el redondeamiento de las rocas. El curso que viene en dirección NW se deflecta en dirección NE en dirección al trazo de la falla destral de Río Seco.

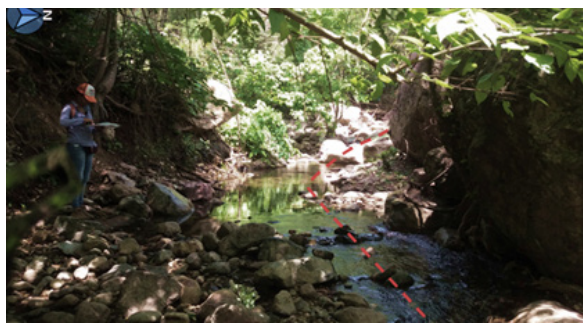

\section{Figura 9.}

Curso fluvial deflectado Fuente: Autores.

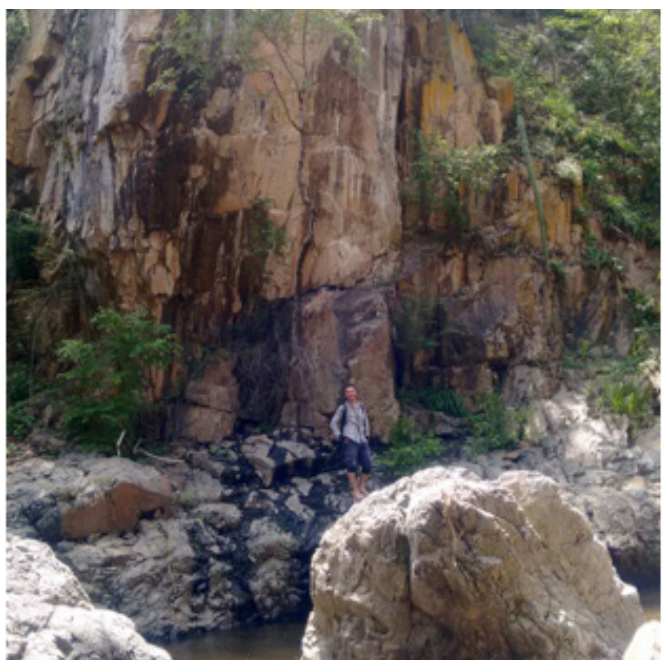

Figura 10.

Diaclasa W-E asociadas al movimiento de la Falla Río Seco Fuente: Autores 
Por lo general, las fallas geológicas presentan espejos característicos de sus movimientos. Sin embargo, dichos movimientos pueden tener réplicas en las diaclasas paralelas a esta. En la Figura 10, se observa diaclasas con movimiento extensional, producto del movimiento de la falla dextral.

\section{Figura 11}

Arroyo Las Palmas controlado por el trazo de la Falla

Rio Seco

Fuente: Autores.

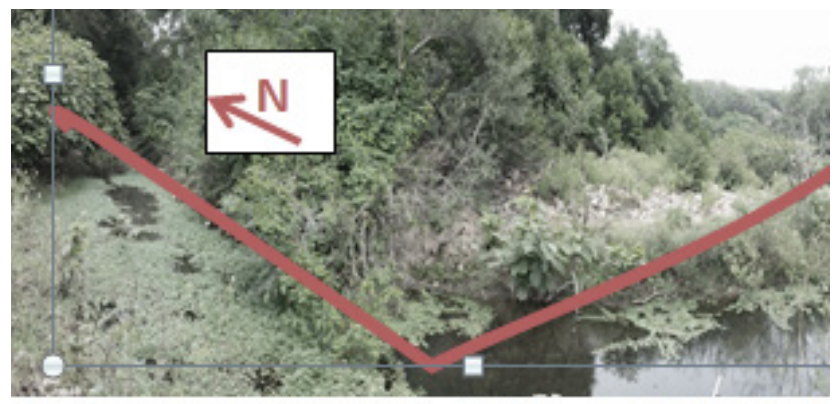

Debe aclararse que, paralelo al Arroyo Las Palmas, se encuentra otro que sigue una dirección predominante N-S y perpendicular a la Falla Río Seco. En el bloque norte de la falla, el arroyo presenta una pequeña desviación en dirección predominante $\mathrm{E}-\mathrm{W}$ en un tramo de alrededor de 12 metros, lo cual es una clara evidencia de que el arroyo ha sido afectado por la misma falla en esta dirección. En su continuación, el arroyo tiende a seguir una dirección N-S (Figura 11).

Otro indicador importante del movimiento de la falla es la presencia de fracturas, ubicadas en lugares poco distantes tanto del arroyo mencionado anteriormente como del trazo de la misma. De estas se tomaron los respectivos datos estructurales, Rumbo y Buzamiento(Figura 12). El primer conjunto de diaclasas está ubicado en el lecho del arroyo, al norte de la falla, con orientación preferencial de N60E/20NW. El segundo conjunto de diaclasas está ubicado en el río principal Río Seco, en la parte sur de la falla, con una orientación preferencial N67E/23NW y en el mismo tramo del río con orientación de N74E/19NW. Tomando como base los datos estructurales de las diaclasas y la orientación preferencial de la Falla E-W, se determinó que están dispuestas en forma paralela a la Falla Rio Seco, lo cual demuestra que corresponden a fracturas asociadas al esfuerzo principal que esta presenta.

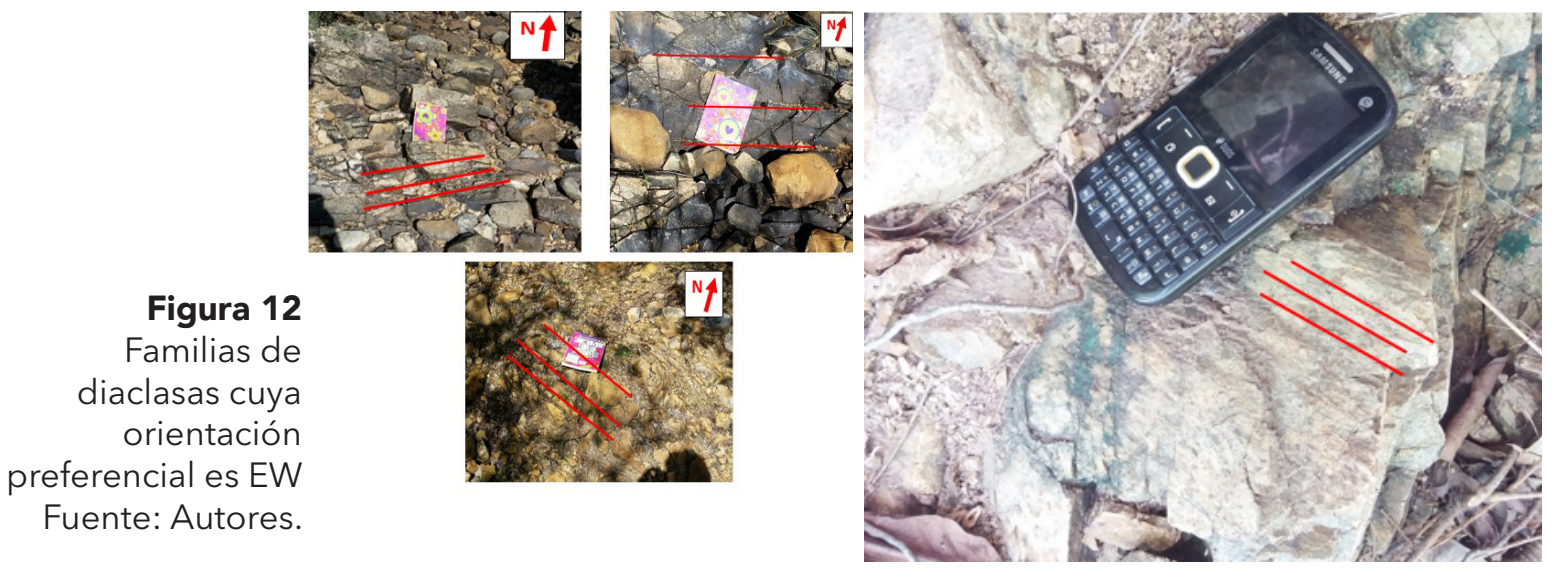

Como citar este artículo: K. Teheran., y L. Tapia, "Análisis neotectónico de la falla río seco, ciudad de Valledupar, Cesar", Investigación e Innovación en Ingenierias, vol. 6, n. 1, pp. 40 - 57. 2018. DOI: https://10.17081/invinno.6.1.2774 
En la parte SW de la zona en dirección a un curso fluvial NE-SW, se ubica un afloramiento de ignimbrita, pequeña falla local con dirección N46E/87NW. Su componente es dextro lateral (Figura 13). Paralelo a esta, el macizo también se encuentra altamente fracturado. En este caso, las diaclasas presentan movimientos, evidenciados por estrías que van en dirección horizontal, lo cual indica que el movimiento de la falla es dextral y es reproducido en las diaclasas paralelas a esta (ver Figura 14).

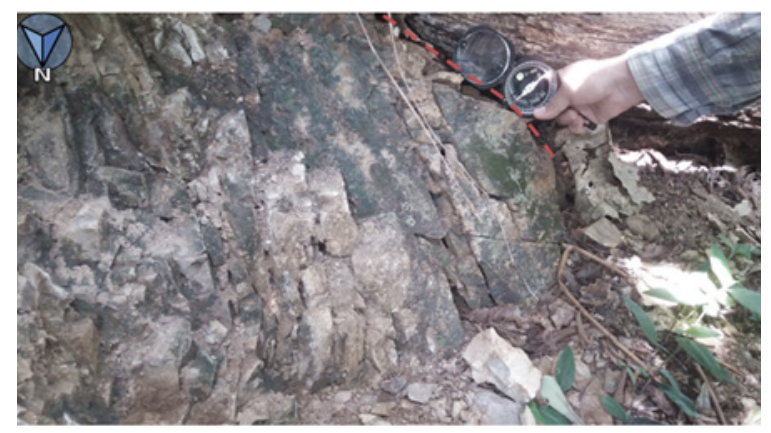

Figura 13.

Falla dextrolateral. Se observa el dato de rumbo del plano de la falla Fuente: Autores

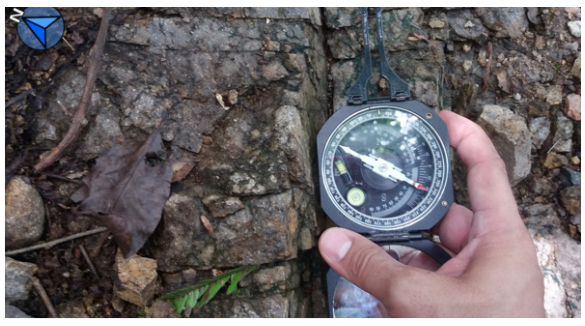

\section{Figura 14.}

Estrías de la falla dextral en dirección WE, reflejadas en una diaclasa Fuente: Autores.

Se puede apreciar un plano de falla con orientación N80E. Esta falla permite el fracturamiento intenso del macizo. En la parte izquierda se observan diaclasas con orientación preferencial NEE y en la parte derecha, las diaclasas cambian su orientación a NS (Figura 15).

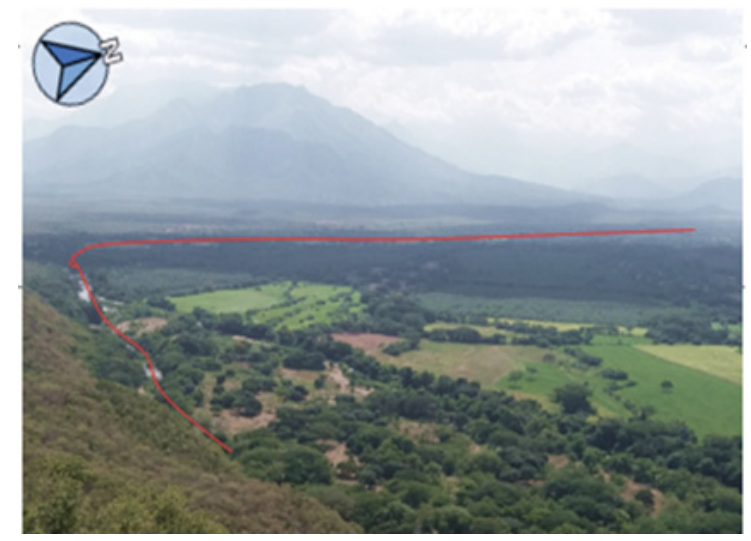

\section{Figura 15.}

Plano de falla. Se observan diaclasas asociadas con la falla Fuente: Autores.

Hay otros indicadores estructurales que se reflejan en el curso del Río Badillo, el cual fluye en dirección NW-SE y es deflectado por la falla en dirección WE, como se observa en la Figura 16. 
Figura 16

Curso fluvial que

va en dirección

NW-SE es

deflectado por la

Falla Río Seco en dirección WE

Fuente: Autores.

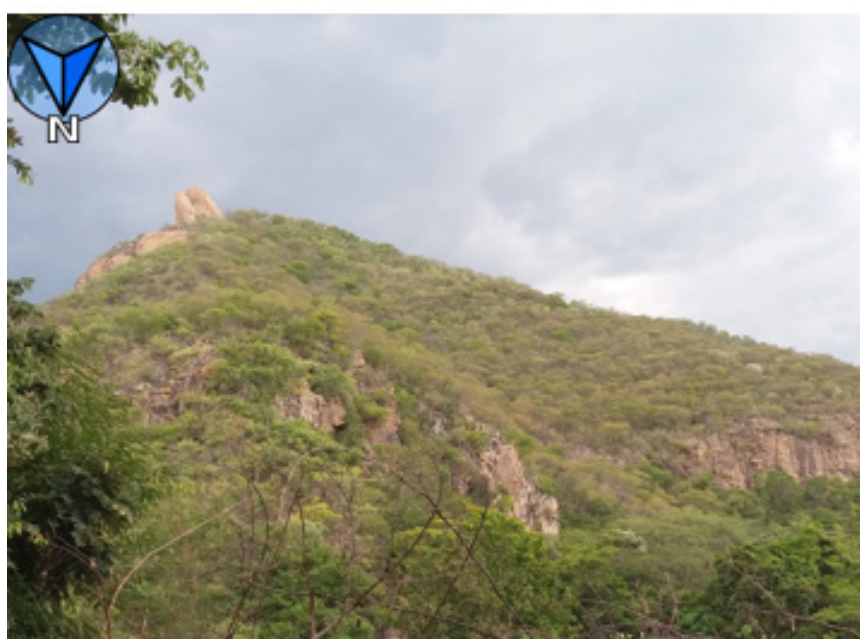

Aunque la Falla Río Seco es de carácter dextro lateral [10], se evidencia un componente vertical de la misma en algunas geoformas presentes en el área. En la Figura 17 se observa concretamente un escarpe de falla que va en dirección EW y que coincide con su trazo. El escarpe es reciente, pues no ha sido desmantelado por la erosión. Otro indicador del movimiento vertical de la falla es un SagPond ubicado en el bloque norte (Figura 18). Ello indica que este bloque se encuentra en un nivel inferior al bloque Sur.

\section{Figura 17 \\ Laguna de subsidencia \\ (sagpond)}

Fuente: Autores.

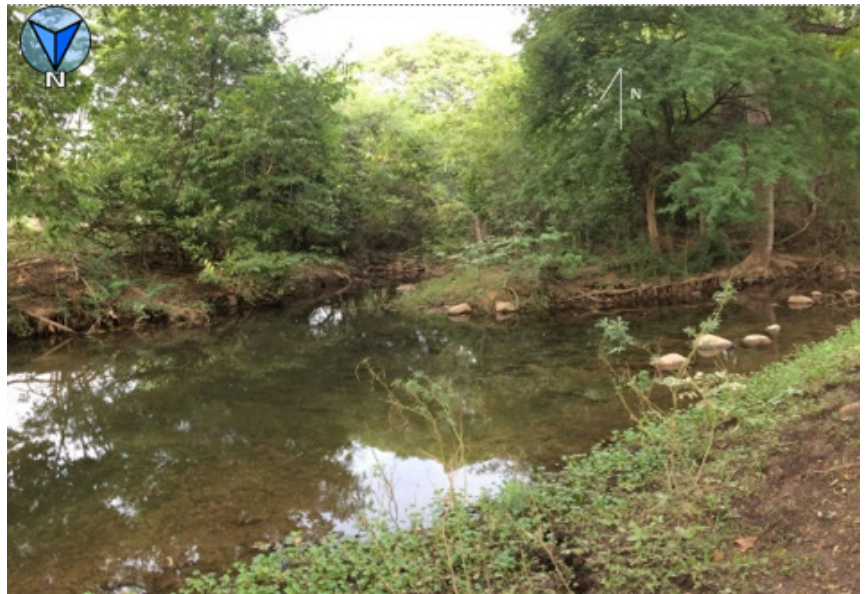

En general los datos presentados brindan un acercamiento cualitativo para la comprensión de su evolución estructural. En la Tabla 2, se relacionan los datos estructurales tomados en las diferentes estructuras presentes, y direcciones de esfuerzos determinadas según las fallas mesoscópicas y las diaclasas.

Como citar este artículo: K. Teheran., y L. Tapia, "Análisis neotectónico de la falla río seco, ciudad de Valledupar, Cesar", Investigación e Innovación en Ingenierias, vol. 6, n. 1, pp. 40 - 57. 2018. DOI: https://10.17081/invinno.6.1.2774 


\begin{tabular}{|l|l|}
\hline Dip & Dip Direction \\
\hline 20 & 330 \\
\hline 23 & 337 \\
\hline 19 & 344 \\
\hline 87 & 316 \\
\hline 88 & 334 \\
\hline 76 & 297 \\
\hline 89 & 311 \\
\hline 49 & 320 \\
\hline 86 & 199 \\
\hline 63 & 84 \\
\hline 31 & 55 \\
\hline 52 & 308 \\
\hline
\end{tabular}

Tabla 2.

Datos estructurales tomados en campo

Una vez relacionados estos datos estructurales, se realizó la representación en el diagrama de rosa, obteniendo como resultado la orientación preferencial. Se concluye así que esta zona presenta un dominio estructural al NE y que ha sido influenciado por el movimiento dextral de la Falla Río Seco (Figura 18).

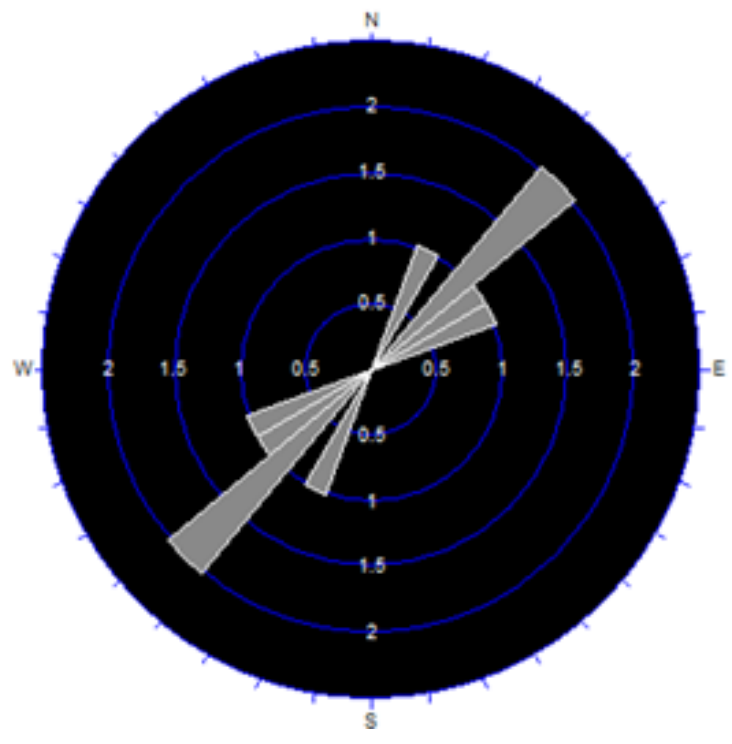

Figura 18.

Diagrama de rosa con intervalos de clase 40. La mayor concentración de datos estructurales tiene orientación al NE Fuente: Autores. 


\section{Análisis neotectónico}

Para la realización de la cartografía neotectónica se parte de dos mapas base: el mapa geológico y el mapa geomorfológico, en los que se presentan todas las unidades afectadas por la falla.

En este caso, se identifica la alineación del Río Seco en dirección EW producido por el trazo de la falla: un manantial producto de la humedad característica de estos procesos tectónicos, un sagpond, cursos fluviales deflectados, estructuras, diaclasas y fallas menores asociadas al trazo de la falla (Figura 19). Debido a estos cambios tectónicos y morfotectónicos, la Falla Río Seco corta efectivamente el cuaternario. Las geoformas presentes en el trazo de la falla se hallan alineadas a esta, evidenciando su actividad tectónica reciente. Además, se comprueban las actividades sísmicas históricas registradas anteriormente, que están próximas a ella y pueden relacionarse con el movimiento de esta.

\section{MAPA NEOTECTÓNICO}

Figura 19

Mapa

Neotectónico

Fuente: Autores.
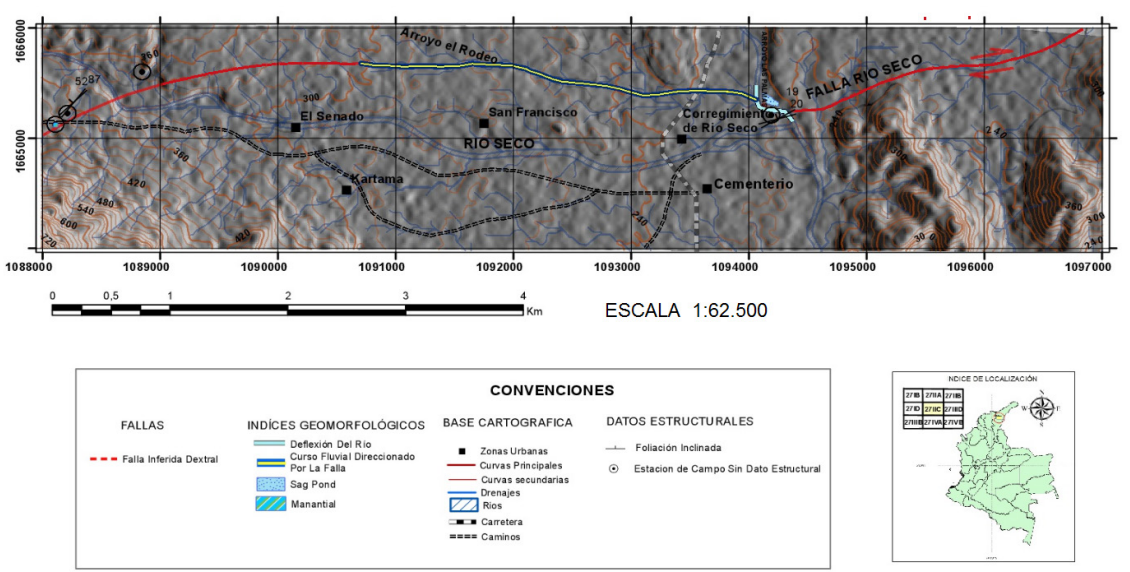


\section{$\varnothing$ \\ Conclusión}

Los indicadores geomorfológicos son una evidencia de la actividad y trazo de una falla. La deflexión del arroyo las Palmas, la presencia de un sagpond, geoformas tectónicas como manantiales, río deflectado, silletas de falla, además de un cambio de escasa a abundante vegetación constituyen criterios neotectónicos que reflejan el estado activo de la Falla Río Seco.

A partir de la medición de datos estructurales como rumbo y buzamiento a las familias de diaclasas presentes en los afloramientos, se determinó que las orientaciones de las mismas están relacionadas con la orientación preferencial de la Falla Río Seco E-W, asociadas a su esfuerzo principal.

Es de resaltar que al mismo tiempo que la tectónica de la Falla Río Seco actúa como agente modelador de la superficie terrestre, también se evidencia una serie de procesos de erosión y sedimentación, lo que no permite identificar todos los cambios generado por la acción de esta falla.

En el mapa neotectónico se evidencian los indicadores de la actividad de la falla, corroborando la dirección y extensión de la misma; de igual forma, el mapa permitió evidenciar el trazo de la falla Río Seco y las estructuras que ha dejado, como rasgos a lo largo del tiempo geológico sobre el cual ha tenido actividad.

Teniendo en cuenta la información obtenida a partir del Servicio Geológico Colombiano, en la zona aledaña a la Falla Río Seco se ha evidenciado en los últimos años un aumento de la actividad sísmica, que, por lo que es netamente indispensable modificar el mapa de amenazas y riesgos de la ciudad de Valledupar e implementar medidas de prevención, antes de que ocurra un sismo de gran magnitud. La evaluación de la amenaza sísmica en Colombia tiene limitaciones. Es por esto que estudios neotectónicos como el realizado para la determinación del movimiento reciente de la Falla Río Seco sirve como base para la actualización del mapa de amenaza sísmica del municipio de Valledupar. Asimismo, el trabajo puede ser asumido como un estudio piloto que estimule otros similares para contribuir a la actualización del mapa de amenaza de la región estudiada. 


\section{Referencias}

1. C. Ortega. "Proyecto multipropósito los besotes". Instituto Colombiano de Geología y Minería dirección del servicio geológico. Inédito. Valledupar. 2014.

2. A. Ordaz, J. Hernández, C. Cofiño, A. Méndez, G. Galaz. "Análisis estructural y morfotectónico en los municipios San Cristóbal y Candelaria, Cuba Occidental: contribución a los estudios de peligrosidad sísmica de la Falla Pinar”. IG, vol. 2013, pp 7-23. Diciembre, 2013. DOI: dx.doi.org/10.14350/rig.36384 3. G, Bayona, et al "Paleomagnetic data and K-Ar ages from Mesozoic units of the Santa Marta Massif: A preliminary interpretation for block rotation and translations". Jsames. vol. 29, pp 817-831. Octubre, 2010. DOI: http://dx.doi.org/10.1016/j.jsames.2009.10.005

4. E. Rojas, M. Fortich, H. Pavajeau. "Determinación del origen y la composición de las aguas termales ubicadas en los municipios de Becerril (Cesar) y Ciénaga (Magdalena), Colombia”. Ingenium, vol. 8, no. 21, pp 35-42. Septiembre, 2014. DOI: http://dx.doi.org/10.21774/ing.v8i21.441

5. C. Montes et al. "Clockwise Rotation of the Santa Marta Massif and Simultaneous Paleogene to Neogene Deformation of the Plato-San Jorge and Cesar-Rancheria Basins". Journal of South American Earth Sciences. pp. 832-848. 2010. DOI: http://dx.doi.org/10.1016/j.jsames.2009.07.010

6. G. Nova. "Contribuciones paleomagnéticas y geocronológicas sobre la paleogeografía del Jurásico en la Serranía del Perijá”. GC, vol 7, no. 1, Bogota, 2012. DOI: 10.15446/gc

7. C. Ortega. "Proyecto multipropósito los besotes". Instituto colombiano de geología y minería dirección del servicio geológico. Inédito. Valledupar. 2014.

8. C. Ortega, E. Rojas, D. Manco. "Mineralización de cobre en el sector de San Diego, Serranía del Perijá.”. Medellin. Gc, vol 37, no. 2, pp.51-62. 2015. DOI: 10.15446/gc

9. C. Ortega. "Evaluación tectónica y sismológica y despliegue de la red sismológica portátil en el área del proyecto multipropósito los besotes". Inédito. Instituto colombiano de geología y minería. Dirección del servicio geológico. Valledupar. 2010.

10. Servicio Geológico Colombiano. Red sismológica nacional de Colombia. Agosto, 2015.

Como citar este artículo: K. Teheran., y L. Tapia, "Análisis neotectónico de la falla río seco, ciudad de Valledupar, Cesar", Investigación e Innovación en Ingenierias, vol. 6, n. 1, pp. 40 - 57. 